\title{
MENGEMBANGKAN POTENSI ENERGI TERBARUKAN DI JARINGAN IRIGASI DENGAN PEMBANGKIT LISTRIK TENAGA MIKRO HIDRO (PLTMH)
}

\author{
Suwignyo ${ }^{1}$ \\ Sekretaris Pusat Penerapan Dan Pekajian Eergi Baru Terbarukan (P3EBT) UMM \\ Staf Pengajar Jurusan Teknik Sipil ${ }^{1}$ \\ Fakultas Teknik - Univ. Muhammadiyah Malang \\ Kampus III, Jl. Tlogomas No. 246 Telp. (0341) 464318-319 Pes. 130 Fax. (0341) 460435 \\ e-mail: wignyo_08@yahoo.com
}

\begin{abstract}
Power Generation Potential Micro Hydro Mini \& Micto Hydro (PLTM \& PLTMH) in Indonesia reached 0.45 GWatt, has been developed for 0084 GWatt (18\%). One potential PLTM \& PLTMH is irrigation networks, both new irrigation networks and existing irrigation networks. Wide of †rice fields in Indonesia are 6134 million ha, consisting of 19,344 technical irrigation network mainly scattered in the island of Java, Sumatra, Sulawesi, Bali and West Nusa Tenggara Province. Year 2005 has been successfully built the capacity of $100 \mathrm{~kW}$ PLTMH Melong exploit irrigation networks were involved networks fall building in Curug Agung in Subang district. PLTMH produced 700,800 KWh of energy per year, medium voltage network interconnected with PLN. In April 2008 this power of Micro Hydro Power (PLTMH) with a capacity of $100 \mathrm{~kW}$ operating in Campus University Muhammadiyah of Malang (UMM) and this is collaboration result of UMM with the National Research and Development ( Balitbang) Ministry of Energy and Mineral Resources of Indonesia. UMM PLTMH Development is to promote the use of renewable energy sources as part of efforts to overcome the energy crisis as well as efforts to decrease greenhouse gas emissions that cause global warming. One type of renewable energy sources are small -scale water or micro- hydro. Development of PLTM \& PLTMH in irrigation networks can be done in the main building, building falls, and buildings structures to complement that have a high hydraulic fall. The study on an irrigation network D.I. in Kedungkandang Malang shows that the potential power in buildings comes up in irrigation on the main channel reaches about 1 MWatt.
\end{abstract}

Key words: power, micro hydro, irrigation channels

\section{PENDAHULUAN}

Saat ini hampir semua wilayah di Tanah Air masih mengalami krisis pasokan tenaga listrik termasuk di wilayah Jawa-Bali. Pada tahun 2005, beban puncak sistem interkoneksi Jawa-Bali mencapai 15.830 MW, sedangkan kapasitas terpasang pembangkit PT PLN 19.615 MW dan daya listrik yang dapat disalurkan sebesar 18.398 MW. Artinya system kelistrikan Jawa-Bali mempunyai cadangan $17 \%$ lebih rendah daripada cadangan normal minimal sebesar $30 \%$. Kebutuhan akan tenaga listrik terus meningkat sejalan dengan pertumbuhan ekonomi di Indonesia. Pada tahun 2008 permintaan pasokan tenaga listrik telah mencapai 40.000 MW sedangkan kapasitas produksi listrik oleh PT PLN hanya sekitar 29.000 MW. Dengan meningkatnya pertumbuhan ekonomi di Indonesia sebesar $\pm 6 \%$ per tahun, maka idealnya peningkatan produksi tenaga listrik minimal 1,5 kalinya atau $\pm 9 \%$ per tahun (Jawa Pos,28 Juni 2008).

Sebagaimana diketahui bersama, naiknya harga minyak dunia yang pada awal 2007 sekitar 50 US\$ per barel hingga mencapai hampir 90 US\$ per barel (Desember 2007) semakin menaikkan biaya produksi listrik. Biaya produksi tenaga listrik oleh PT PLN per kWH mencapai \pm Rp 1.300,- dan dijual oleh PT PLN kepada pelanggan dengan harga sekitar Rp 630,-/kWH, hal ini semakin menambah besar biaya subsidi yang akan di tanggung oleh Pemerintah. Terlebih lagi cadangan sumber energi 
fosil semakin menipis, maka pemanfaatan sumber energi baru dan terbarukan untuk menambah kemampuan pasokan energi haruslah terus ditingkatkan.

Fast track I pada 2006, pemenuhan tenaga listrik sebesar 10.000 MW diproduksi menggunakan bahan bakar fosil berupa batubara. Namun pada Fast track II tahun 2010, pemakaian batubara sebagai penghasil tenaga listrik di skenariokan hanya menghasilkan $\pm 3.000 \mathrm{MW}$ dan produksi tenaga listrik sebesar $\pm 7.000 \mathrm{MW}$ sisanya akan menggunakan energi terbarukan.

Pemerintah juga memprogramkan penyediaan tenaga listrik yang murah dan efisien dengan menargetkan pemenuhan produksi tenaga listrik sebesar $\pm 3.000 \mathrm{MW}$ (hidro) dan $\pm 1.000 \mathrm{MW}$ (geothermal) sehingga diharapkan penggunaan BBM untuk pembangkitan tenaga listrik hanya sebesar $\pm 2 \%$ pada tahun 2016. Panas bumi (geothermal) sebagai salah satu sumber energi listrik, memiliki potensial pembangkitan listrik \pm 27.000 MW dan baru termanfaatkan sebesar 1000 MW, sedangkan air dengan potensial pembangkitan $\pm 50.000 \mathrm{MW}$ telah termanfaatkan sebesar 3000 MW. Pemerintah juga menargetkan dalam 5-10 tahun ke depan akan mengembangkan dan memanfaatkan potensi-potensi energi pembangkit listrik yang ada sebesar $10.000 \mathrm{MW}$ begitu juga dengan rencana penawaran kerjasama dengan pihak swasta untuk membangun pembangkit tenaga listrik skala kecil (PSK, dibawah $1 \mathrm{MW}$ ) dan PT. PLN akan membeli seharga $80 \%$ dari harga jual.

Terkait dengan pemanasan global, turunnya pemakaian energi fosil secara tidak langsung akan menurunkan emisi karbondioksida, salah satu gas rumah kaca penyebab pemanasan global (global warming). Pemanasan global inilah yang menyebabkan terjadinya perubahan iklim berikut dampak ikutannya seperti kegagalan panen, kelangkaan air, tenggelamnya daerah pesisir, banjir, dan kekeringan. Sebagaimana diketahui, sekitar 63\% emisi karbondioksida dihasilkan oleh sektor industri energi (pembangkit listrik/kilang minyak) dan sektor transportasi.

\section{Potensi Energi Terbarukan}

Data dari Departemen ESDM (Yusgiantoro, 2006) sebagaimana terlihat pada Tabel 1, menunjukkan bahwa pada Tahun 2005 hanya sebagian kecil dari potensi sumber energi terbarukan yang sudah termanfaatkan. Tenaga air baru terpasang 4,2 GW (5,55\%) dari potensi 75,67 GW. Karena itu sangatlah bisa dimengerti jika pemerintah berusaha menaikkan target pemakaian sumber energi terbarukan

\section{Tabel 1. Potensi Sumber Energi Baru Terbarukan}

\begin{tabular}{cccc}
\hline JENIS SUMBER ENERGI & SUMBER DAYA & SETARA & KAPASITAS TERPASANG \\
\hline Tenaga Air & 845.00 juta BOE & $75.67 \mathrm{GW}$ & $4.2 \mathrm{GW}$ \\
Panas Bumi & 219.00 juta BOE & $27.00 \mathrm{GW}$ & $0.8 \mathrm{GW}$ \\
Mini/Micro Hydro & $0.45 \mathrm{GW}$ & $0.45 \mathrm{GW}$ & $0.084 \mathrm{GW}$ \\
Biomass & $49.81 \mathrm{GW}$ & $49.81 \mathrm{GW}$ & $0.3 \mathrm{GW}$ \\
Tenaga Surya & - & $4.80 \mathrm{kWh} / \mathrm{m} 2$ hari & $0.008 \mathrm{GW}$ \\
Tenaga Angin & $9.29 \mathrm{GW}$ & $9.29 \mathrm{GW}$ & $0.0005 \mathrm{GW}$ \\
\hline
\end{tabular}




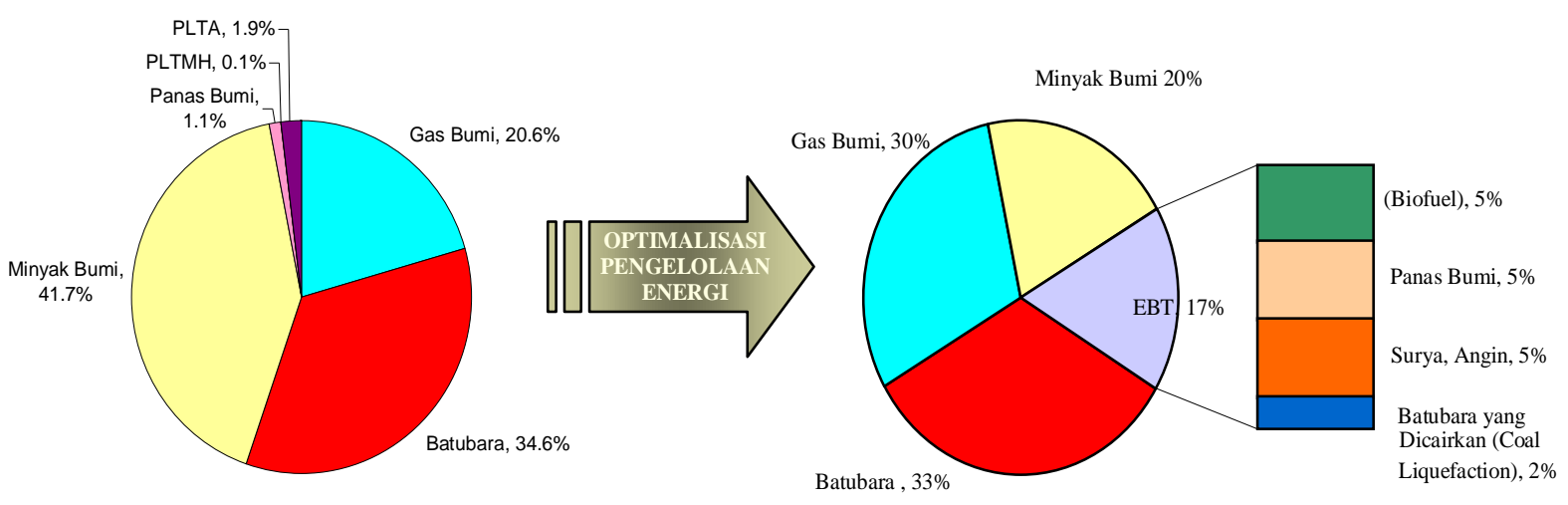

\section{Gambar 1. Diagram Diversifikasi Energi}

Sesuai Perpres No. 5/2006, untuk optimalisasi pengelolaan energi, pada Tahun 2025 Departemen ESDM menargetkan pemakaian sumber energi baru terbarukan sebesar $17 \%$, jauh lebih besar daripada kondisi tahun 2005 sebesar 4,43\% (Gambar 1). Pemakaian energi fosil (minyak bumi dan batubara) ditargetkan sebesar 53\%, turun dari pada kondisi tahun 2005 sebesar $77 \%$.

\section{Potensi Saluran Irigasi di Indonesia}

Indonesia memiliki sawah irigasi teknis 6,134 juta ha, terdiri dari 19.344 daerah irigasi yang tersebar di seluruh Indonesia, terutama di P. Jawa, P. Sumatera dan P.Sulawesi. Disetiap jaringan irigasi teknis terdapat beberapa bangunan terjun dan bangunan sadap yang memiliki tinggi jatuh hidrolik, sehingga mempunyai potensi untuk dikembangkan sebagai PLTMH. Pengembangan PLTMH dengan memanfaatkan saluran irigasi, merupakan phenomena menarik tentang diversifikasi fungsi jaringan irigasi yang selama ini hanya dititikberatkan pada pemanfaatan untuk irigasi pertanian.

Apalagi dengan laju pertumbuhan penduduk yang relatif cepat dan kebutuhan akan pemilikan lahan hunian di sebagian wilayah di Indonesia, menyebabkan air yang mengalir di saluran irigasi ini tidak lagi termanfaatkan secara maksimal karena menyusutnya lahan pertanian yang seharusnya dialiri air rigasi yang berubah fungsi menjadi kawasan pemukiman dan industri. Di sebagian wilayah yang lain saluran irigasi telah berubah fungsinya menjadi saluran drainase. Karena itu akan lebih bermanfaat apabila air yang sudah tidak termanfaatkan untuk lahan pertanian ini dijatuhkan kembali ke sungai asal sebagai sumber energi untuk pembangkit listrik.

Tabel 2. Data Daerah Irigasi di Indonesia, 2006

\begin{tabular}{|c|c|c|c|c|c|c|c|c|c|c|c|}
\hline \multirow[t]{3}{*}{ Pulau / Nasional } & \multirow[t]{3}{*}{$\begin{array}{c}\text { Jumlah } \\
\text { Irigasi }\end{array}$} & \multirow{3}{*}{$\begin{array}{c}\text { Luas } \\
\text { Rencana } \\
\text { (Ha) }\end{array}$} & \multicolumn{6}{|c|}{ Luas Fungsional (Ada Jaringan Utama) - (Ha) } & \multicolumn{3}{|c|}{$\begin{array}{c}\text { Luas Belum Ada } \\
\text { Jaringan Utama - Ha }\end{array}$} \\
\hline & & & \multicolumn{2}{|c|}{ Sudah Sawah } & \multirow{2}{*}{$\begin{array}{l}\text { Belum } \\
\text { Sawah }\end{array}$} & \multicolumn{2}{|c|}{ Alih Fungsi } & \multirow[t]{2}{*}{ Jumlah } & \multirow{2}{*}{$\begin{array}{l}\text { Sudah } \\
\text { Sawah }\end{array}$} & \multirow{2}{*}{$\begin{array}{l}\text { Belum } \\
\text { Sawah }\end{array}$} & \multirow[t]{2}{*}{ Jumlah } \\
\hline & & & Optimal & $\begin{array}{l}\text { Belum } \\
\text { Optimal }\end{array}$ & & Sawah & $\begin{array}{l}\text { Belum } \\
\text { Sawah }\end{array}$ & & & & \\
\hline Sumatera & 3800 & $1,506,748$ & $1,067,320$ & 163,401 & 200,910 & 18,844 & 1,154 & $2,962,711$ & 248,757 & 131,113 & 379,870 \\
\hline Jawa + Bali & 13000 & $2.853 .730,7$ & $3,230,565$ & 91,256 & 42,899 & 47,552 & 0 & $6,279,002,7$ & 288,254 & 4,628 & $4,716,254$ \\
\hline Nusa Tenggara & 808 & 583,507 & 233,160 & 17,740 & 20,232 & 11,369 & 221 & 867,037 & 269,212 & 31,573 & 300,785 \\
\hline Kalimantan & 853 & $385,216,1$ & 228,960 & 35,457 & 15,391 & 1,89 & 0 & $666,066,1$ & 57,204 & 44,254 & 101,458 \\
\hline Sulawesi & 837 & 741,953 & $4,223,875$ & 30,880 & 64,503 & 31,912 & 627 & $5,094,587$ & 173,725 & 19,428 & $19,601,725$ \\
\hline Maluku & 31 & 41,302 & 23,269 & 4,121 & 1,597 & 881 & 0 & 71,201 & 11,324 & 110 & 121,434 \\
\hline Papua & 15 & 22,150 & 2,122 & 850 & 2,068 & 0 & 0 & 27,205 & 15,810 & 1,300 & 17,110 \\
\hline Indonesia & 19,344 & $6,134,624,8$ & $9,009,271$ & 180,467 & 333,800 & 100,547 & 2,002 & $5,227,470$ & $1,064,286$ & $1,641,048$ & 20.998 .636 \\
\hline
\end{tabular}

Sumber :Suwignyo, 2008 


\section{Environtmental Benefits PLTMH}

emakaian sumber energi air untuk pembangkit tenaga listrik akan menggantikan/ mengurangi pemakaian sumber energi fosil seperti solar. Karena itu turunnya pemakaian energi fosil secara tidak langsung akan menurunkan emisi karbondioksida, salah satu gas rumah kaca penyebab pemanasan global (global warming) yang menyebabkan terjadinya perubahan iklim. Sebagaimana diketahui, sekitar 53\% emisi karbondioksida dihasilkan oleh sektor industri energi (pembangkit listrik/ kilang minyak) dan sektor transportasi

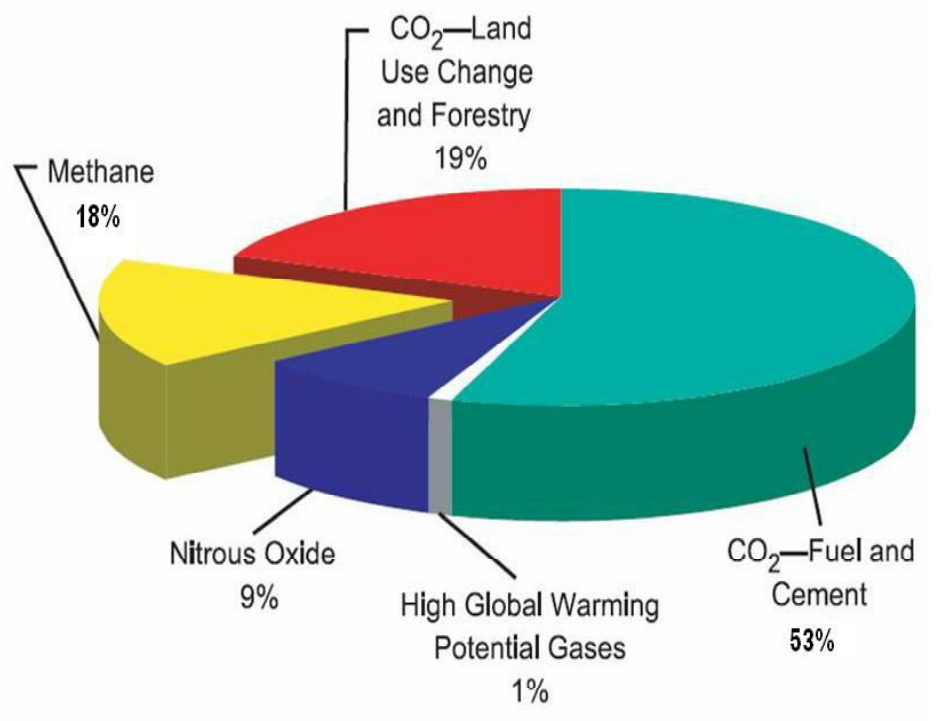

\section{Gambar 2 : Emisi Gas Rumah Kaca}

Menurut Environtmental Protection Agency (EPA) US (http://www.epa.gov), setiap kilowatts listrik hasil pembangkit listrik dengan bahan bakar fosil akan menghasilkan emisi karbondioksida sebesar 0,00076 ton per jam. Sehingga pembangkit listrik dengan kapasitas 1 MW dengan menggunakan energi terbarukan secara tidak langsung akan mereduksi sekitar lebih dari 5.500 ton gas karbondioksida per tahun. Emisi sebesar itu setara dengan emisi 1.000 kendaraan atau reboisasi hutan lebih dari 500 ha. Karena itu masyarakat perlu diberikan contoh yang nyata tentang cara-cara melakukan eksplorasi sumber alam untuk pembangkit listrik yang tidak merusak lingkungan seperti halnya pembangkit listrik tenaga air skala kecil (PLTMH). Persamaan untuk menentukan karbondioksida yang secara tidak langsung dapat dicegah dengan pemanfaatan sumber energi pembangkit listrik dengan tenaga air adalah sebagai berikut:

Produksi karbondioksida $=0.85 \times$ P x t x 0.00076 (ton/ tahun)
Dimana:

$$
\begin{aligned}
& \mathrm{P}=\text { produksi listrik }(\mathrm{kW}) \\
& \mathrm{t}=8760
\end{aligned}
$$

\section{METODELOGI}

\section{Identifikasi potensi PLTMH}

Untuk mengidentifikasi potensi dan kendala dalam pengembangan PLTMH, terdapat 4 (empat) parameter utama yaitu (Sewoyo dan Suwignyo, 2008), yaitu: ketersediaan air, potensi topografi, jarak area pemanfaatan, dan infrastruktur yang ada.

Ketersediaan Air

Kompilasi data debit yang memadai dan analisa ketersediaan air perlu dilakukan secara cermat karena hampir semua PLTMH dibangun dengan memanfaatkan aliran langsung (tanpa waduk). Selain itu debit aliran harus dijamin terpenuhi sepanjang tahun dengan tingkat keandalan tertentu. 


\section{Potensi Topografi / Tinggi Jatuh}

Kondisi topografi menentukan tinggi jatuh efektif. Karena itu pemilihan lokasi terkait dengan kondisi topografi ini haruslah tepat sehingga akan meminimumkan biaya pekerjaan sipil. Semakin besar tinggi jatuh efektif, maka daya terbangkit semakin besar atau dimensi turbin semakin kecil. Sehingga kondisi topografi sangat menentukan terhadap biaya konstruksi per satuan daya ( $\mathrm{Rp} /$ kWatt).

\section{Jarak Area Pemanfaatan}

Pemanfaatan energi listrik dari PLTMH dapat dimanfaatkan secara mandiri / terpisah atau diinterkoneksikan dengan jaringan listrik PLN. Semakin dekat jarak area pemanfaatan, biaya pembangunan jaringan listrik semakin murah, diupayakan jarak area pemanfaatan tidak lebih dari $2 \mathrm{kM}$. Karena kehilangan daya cukup tinggi dan biaya jaringan listrik dapat mencapai $30 \%$ atau lebih dari biaya total pengembangan PLTMH.

\section{Infrastruktur yang ada}

Dalam pembangunan PLTMH, penting untuk dipertimbangkan adanya sarana (terutama jalan) yang sudah ada (existing), agar pembangunan PLTMH menjadi murah dan mudah.

\section{Analisa ketersediaan air}

Analisa ketersediaan air bertujuan untuk menentukan besaran debit yang bisa dimanfaatkan atau yang tersedia sepanjang tahun dengan tingkat keandalan (debit andalan) tertentu. Tingkat keandalan yang dipilih tergantung pada jenis pemanfaatan air dan tingkat kepentingannya. Untuk penyediaan air irigasi ditentukan tingkat keandalan $80 \%$ dan penyediaan air baku ditentukan tingkat keandalan $90 \%$. Sedangkan untuk pembangkit listrik ditentukan tingkat keandalan $95 \%$ atau bahkan $100 \%$.

\section{Pengukuran dan pemetaan}

Pengukuran dan pemetaan rencana lokasi PLTMH bertujuan untuk menetapkan tinggi jatuh total (beda tinggi topografis) dan sebagai dasar perencanaan tata letak PLTMH. Hasil pengukuran digambarkan dalam peta situasi detail skala $1: 500$ s/d $1: 1000$, dilengkapi dengan gambar potongan memanjang rencana jalur pipa pesat.

\section{Perencanaan dan pembangunan PLTMH}

Pengembangan PLTMH diawali dengan kegiatan analisa debit andalan dan penetapan debit desain, serta penentuan tinggi jatuh hidrolik total dari hasil pengukuran dan pemetaan. Berdasarkan besaran debit desain dan tinggi jatuh dapat ditentukan tipe turbin, estimasi daya terbangkit dan kapasitas generator. Selanjutnya diikuti proses desain fasilitas sipil dan fasilitas elektrikal dan di tindak lanjuti dengan proses pembangunan konstruksi, operasional dan pemeliharaan

\section{Daya terbangkit}

Pembangkit Listrik Tenaga Mikrohidro (PLTMH) memanfaatkan debit aliran air dan tinggi jatuh efektif sebagai sumber pembangkitan. Produksi energi listrik tahunan dirumuskan sebagai berikut (Trihono S dan Suwignyo, 2008).

$$
\begin{aligned}
& P=\eta \cdot \gamma \omega \cdot g \cdot Q \cdot H_{e f} \\
& E=P \cdot T \cdot N \dot{t} \\
& \text { Dimana : } \\
& \mathrm{P} \quad=\text { daya terbangkit, } \mathrm{k} \mathrm{W} \\
& \mathrm{c} \quad=\text { efisiensi total } \\
& \text { âw }=\text { berat volume air, } \mathrm{kg} / \mathrm{m}^{3} \\
& \mathrm{~g} \quad=\text { percepatan grafitasi, } \mathrm{m} / \mathrm{dt}^{2} \\
& \mathrm{Q}=\text { debit air, } \mathrm{m}^{3} / \mathrm{dt} \\
& \mathrm{Hef}=\text { tinggi jatuh efektif, } \mathrm{m} \\
& \mathrm{T} \quad=\text { waktu operasi harian, jam } \\
& \mathrm{Ni} \quad=\text { jumlah hari operasi dalam setahun }
\end{aligned}
$$

\section{HASIL DAN PEMBAHASAN}

Potensi energi dan pengembangan pltmh Di jaringan irigasi

\author{
Studi Kelayakan dan Studi Lingkungan PLTMH \\ UMM
}


Salah satu jaringan irigasi yang mempunyai potensi untuk pengembangan PLTMH adalah jaringan irigasi Sengkaling kiri yang melintas di area kampus Universitas Muhammadiyah Malang (UMM). Di kawasan Kampus UMM mengalir Sungai Brantas dimana sekitar 800 meter dari Kampus UMM terdapat Dam Sengkaling yang ada di Sungai Brantas tersebut. Dari Dam Sengkaling ini dialirkan air ke areal persawahan di wilayah Kota Malang melalui Saluran Irigasi Sengkaling Kanan dan Saluran Irigasi Sengkaling Kiri. Dengan semakin berkurangnya jumlah baku sawah yang diairi dari 691,00 Ha pada tahun 1990 tinggal 193,00 Ha pada tahun 2000 (Baku Sawah Sengkaling Kiri awal $\pm 1000 \mathrm{Ha}$ ) dan dari 193,00 Ha pada tahun 2000 tinggal 173,00 Ha pada tahun 2001 (Baku Sawah Sengkaling Kanan awal \pm 1200 Ha), maka potensi sumber air yang tersisa inilah yang dijadikan sumber energi pembangkit listrik (Suwignyo, 2006 dan Syayuti \& Agus Cahyono, 2002). PLTMH UMM memanfaatkan Saluran Sengkaling Kiri dengan debit $1,00 \mathrm{~m}^{3} / \mathrm{dt}$ yang dijatuhkan kembali ke Sungai Brantas dengan ketinggian $15 \mathrm{~m}$ sehingga menghasilkan listrik sebesar $100 \mathrm{kWatt} 720.000 \mathrm{kWH}$ per tahun.

Untuk pembangunan PLTMH disyaratkan untuk memenuhi kelayakan lingkungan dengan studi UKL \& UPL. Pengelolaan dan pemantauan lingkungan dilaksanakan selama pelaksanaan konstruksi dan secara berkala pasca konstruksi (masa operasional dan pemeliharaan) selama umur fungsional PLTMH.

\section{Debit Andalan PLTMH UMM}

Berdasarkan pencatatan dan kompilasi data debit Sungai K. Brantas di Dam Sengkaling selama 17 tahun terakhir (1990 s/d 2006) dan kebutuhan air irigasi Daerah Irigasi (DI) Sengkaling Kiri dan Kanan, debit anadalan untuk PLTMH UMM sebagai debit perencanaan ditetapkan $0,95 \mathrm{~m}^{3} / \mathrm{dt}$.

\section{Penentuan Tinggi Jatuh Efektif PLTMH UMM}

Hasil pengukuran topografi di lokasi PLTMH UMM menghasilkan data sebagai berikut:
- $\quad$ Elevasi bangunan sadap (hulu $)=+570,00$

- $\quad$ Elevasi rumah pembangkit (hilir) $=+556,26$

- Elevasi dasar sungai $=+550,20$

- $\quad$ Tinggi jatuh brutto $=17,05 \mathrm{~m}$

Perhitungan kehilangan tinggi tekan mayor dan minor sebesar 2,10 m.

Tinggi jatuh efektif

$=17,05-2,10=14,95 \mathrm{~m}$

\section{Daya Terbangkit PLTMH UMM}

Daya terbangkit PLTMH UMM didasarkan data teknik sebagai berikut :

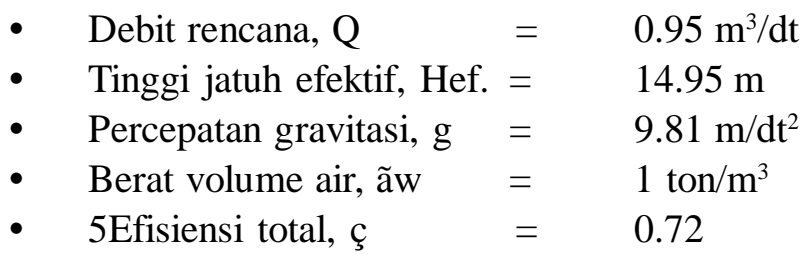

Hasil perhitungan daya terbangkit adalah:

$\mathrm{P}=0.72 \times 1 \mathrm{ton} / \mathrm{m}^{3} \times 9.81 \mathrm{~m} / \mathrm{dt}^{2} \times 0.95 \mathrm{~m}^{3} / \mathrm{dt}$ $\mathrm{x} 14.95 \mathrm{~m}=100 \mathrm{~kW}$

Sedangkan untuk produksi listrik tahunan, didapatkan nilai sebagai berikut :

$\mathrm{E}=100 \mathrm{~kW} \times 300$ hari/thn $\times 24 \mathrm{jam}=720.000$ $\mathrm{kWH} /$ tahun.

\section{Turbin dan Generator PLTMH UMM}

Turbin yang digunakan dalam PLTMH ini adalah turbin cross-flow buatan dalam negeri. Data hasil studi perencanaan digunakan untuk memilih tipe turbin dari grafik pada Gambar 3 (Raharjo, K, 2006) 


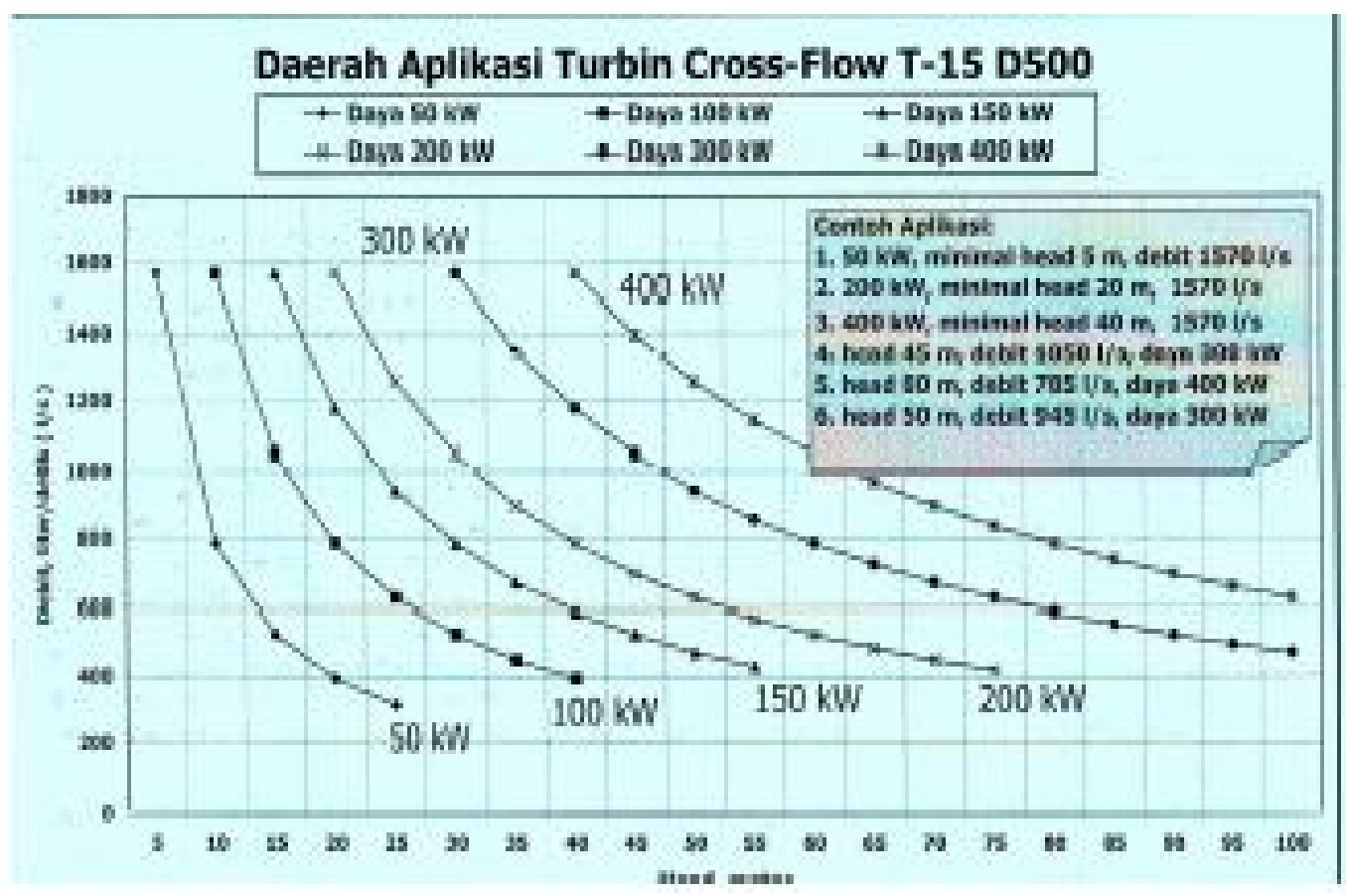

Gambar 3: Daerah aplikasi Turbin T-15 D500

Bagian-bagian utama dari rumah pembangkit by dan stop). Turbin ini menggunakan ballast load dan turbin cross-flow dapat dilihat pada Gambar 4. Sudu pengarah (guide vane) digerakkan menggunakan aktuator hidrolik dengan counter weight. Sudu pengarah ini digunakan untuk pengontrolan operasional turbin (start, run, stand

atau dummy load untuk pengontrolan beban. Dismantling joint didesain untuk memudahkan pemasangan pipa adapter turbin pada pipa pesat (penstock) sekaligus memudahkan saat overhaul.

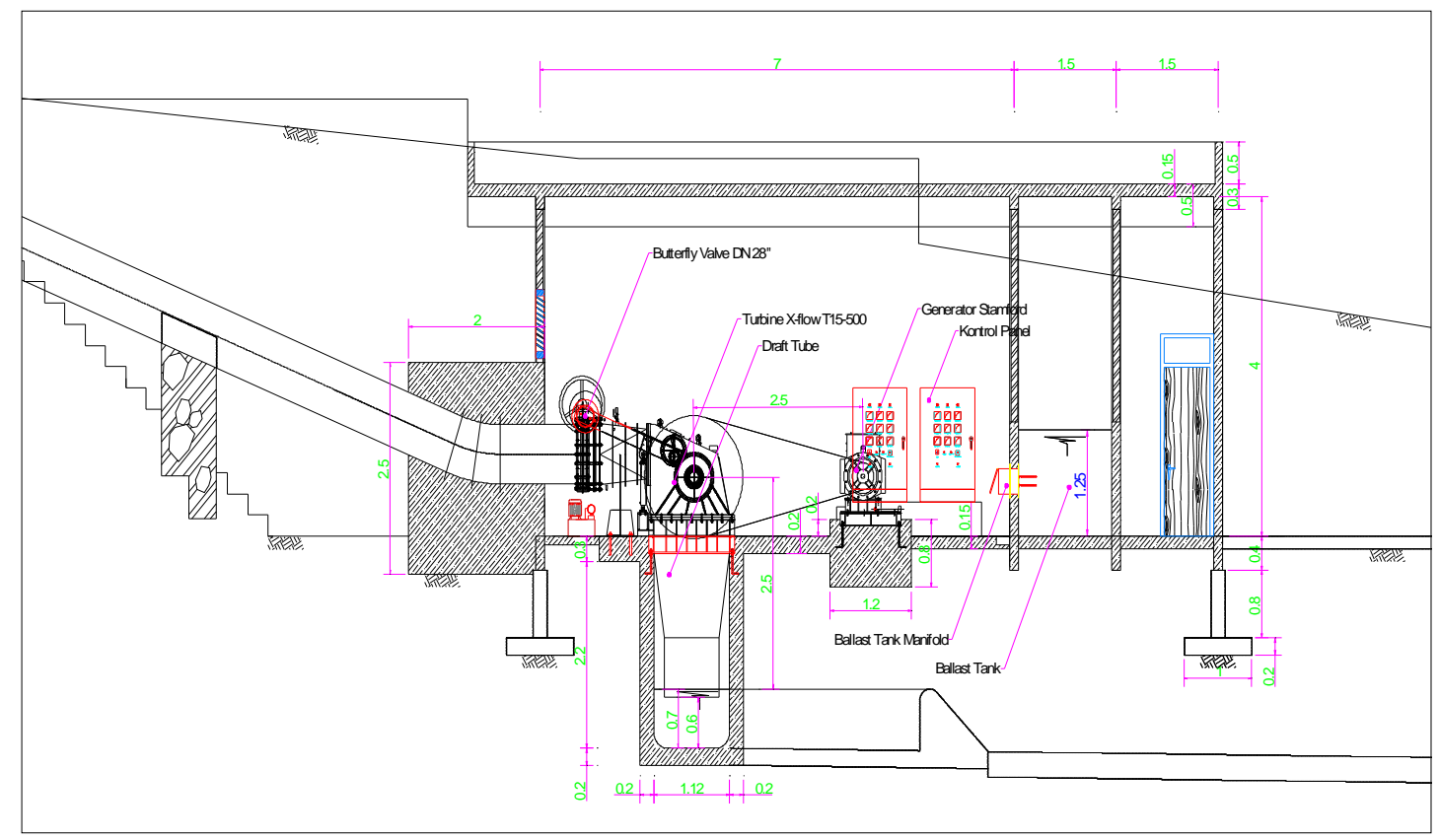

Gambar 4. Rumah Pembangkit, Turbin T-15 D500 dan Generator. 
Kombinasi antara proteksi beban via ballast load (beban dialirkan dulu ke ballast load pada saat terjadi pelepasan beban) dan diikuti dengan penutupan guide vane turbin via aktuator hidrolik merupakan solusi untuk mengatasi water hammer yang biasa terjadi pada governor konvensional. Generator yang digunakan adalah Generator Sinkron $162 \mathrm{~kW}, 50 \mathrm{~Hz}$ merek Stamford dan dilengkapi dengan ELC-sinkro. ELC-SINKRO pada hakekatnya adalah governor hidrolikelektronik berupa kombinasi pengatur beban ELC1 dengan synchronizer PCD-SINKRO yang berbasis teknologi digital.

\section{Pembangkit Listrik Tenaga Mikro Hidro (PLTMH) Melong Subang}

Tahun 2005 telah berhasil dibangun PLTMH Melong yang terletak di Desa Jambel Aer Kecamatan Kalijati Kabupaten Subang. PLTMH ini memiliki kapasitas $100 \mathrm{~kW}$ yang memanfaatkan bangunan terjun di jaringan irigasi Curug Agung di Kabupaten Subang. PLTMH ini menghasilkan energi $700.800 \mathrm{kWh}$ per tahun, diinterkoneksikan dengan jaringan tegangan menengah PLN.

Instalasi turbin di PLTMH Melong Subang menggunakan turbin tipe cross-flow Tandem unit 2 x T-15 D500 Bo 1260 dengan tinggi jatuh 6 m, memakai generator stamford $140 \mathrm{kVA}, 1500 \mathrm{RPM}$, 220/380 V (PT. Heksa Prakarsa Teknik, Bandung).

\section{Potensi Energi Terbarukan di Jaringan Irigasi Kedungkandang Malang}

Di Jaringan Irigasi (JI) Kedungkandang Kabupaten Malang pada saluran primer mempunyai 22 bangunan terjun dan 6 bangunan sadap yang memiliki tinggi jatuh hidrolik $2.0-3.5 \mathrm{~m}$. Dengan potensi daya terbangkit $10 \mathrm{~s} / \mathrm{d} 80 \mathrm{kWatt}$, total potensi daya terbangkit yang dapat dikembangkan di J.I Kedungkandang \pm 1 MW. Potensi energi listrik mencapai 7.92 MWh (Suwignyo, 2007).

\section{Environmental Benefits}

Sebagai contoh environmental benefits, diambil studi kasus pada Pembangkit Listrik Tenaga Mikro Hidro (PLTMH-UMM \& Melong). Telah diketahui kapasitas produksi listrik PLTMH UMM \& Melong sebesar $100 \mathrm{~kW}$, berdasarkan persamaan yang dikemukakan oleh EPA US, produksi karbon yang dapat dicegah dengan adanya PLTMH UMM ini adalah sebesar 570 ton/ tahun. Produksi listrik sebesar $100 \mathrm{~kW}$ dari PLTMH ini akan meniadakan penggunaan 200.000 liter bahan bakar fosil. Sedangkan emisi sebesar 570 karbondioksida per tahun setara dengan peniadaan 100 mobil atau penghijauan kembali lebih dari $50 \mathrm{Ha}$ hutan.

\section{KESIMPULAN}

Jaringan irigasi mempunyai potensi energi terbarukan yang dapat dikembangkan dengan pembangunan pembangkit listrik tenaga mikro hidro (PLTMH). PLTMH UMM yeng memanfaatkan dengan daya 100 kWatt, menghasilkan energi $720.000 \mathrm{kWH}$ per tahun atau setara dengan penggunaan 200.000 liter bahan bakar fosil. PLTMH UMM juga akan menghindari terjadinya penambahan emisi karbondioksida sebesar 570 ton per tahun, sehingga akan mengurangi konsentrasi gas rumah kaca di atmosfir penyebab pemanasan global.

\section{DAFTAR PUSTAKA}

Departemen ESDM Republik Indonesia (2003), "Kebijakan Pengembangan Energi Terbarukan dan Konservasi Energi (Energi Hijau)"

Mahmudsyah, S, (2007), "Pemetaan dan Identifikasi Energi Alternatif/ Energi Terbarukan Potensial di Wilayah Jawa Timur", Surabaya.

Raharjo, K, (2006), "Draft Design Teknik dan Drawings - PLTMH Sengkaling UMM", Universitas Muhammadiyah Malang - PT. Heksa Prakarsa Teknik, Bandung.

Sayuti dan Agus Cahyono, (2002), "Studi Kelayakan Pembangunan PLTMH di Saluran Irigasi", Tugas Akhir S1, Universitas Muhammadiyah Malang, Malang. 
Sewoyo, T dan Suwignyo, (2008), "Pembangkit

Listrik Tenaga Mikro Hidro (PLTMHUMM)", Prosiding Seminar Nasional Potensi Kekayaan Alam Indonesia Sebagai Sumber Energi Alternatif, Politeknik Negeri Malang, Malang.

Suwignyo, (2002), "Pra Desain Pengembangan PLTMH", Universitas Muhammadiyah Malang, Malang.

Suwignyo, (2006), "Review Studi Kelayakan PLTMH UMM", Universitas Muhammadiyah Malang, Malang.

Suwignyo, (2007), "Studi Potensi Mikro Hidro Di J.I. Kedungkandang”, Universitas Muhammadiyah Malang, Malang.

US Environtmental Protection Agency, "Benefits of LFG Energy”, http://www.epa.gov/lmop/ index.htm

Yusgiantoro P.(2006), "Peran Energi Terbarukan dalam Ketahanan Energi Nasional”, Orasi Ilmiah Wisuda UMM 17 Juni 2006 